done in their own homes. One of the major objects in rehabilitation is to enable the disabled person to function in his home within the limits of disability. Some fortunately are able to make adjustments appropriate to their needs; others do remarkably well in managing with what they have but with great difficulty and at a tremendous loss of time and energy. There is an urgent need for housing that meets the special needs of those who lost their mobility, and in this respect I welcome the recent publication of guidance to architects through the R.I.B.A. and the steps taken by the Central Council for the Disabled to give publicity to this need, which may result in substantial future improvement. There is a need for employers, and this could perhaps best be achieved by arrangement with the Welfare Services Department of Local Authorities, to consider whether any part of their work could be undertaken by the severely disabled in their own homes, on an out-worker basis. Some useful forms of production can be achieved in this way; the work involved of necessity must be simple, but it is essential that it should form at least some part of the ultimate production; the severely disabled to be encouraged to do work at home must be convinced that what he is doing is part of a productive effort and not merely an object of recreational handicraft or diversional interest; in the main they do not want to be recipients of sympathy or charity. Nothing can be a substitute for the taking home or receiving a wage packet every week; the severely disabled himself is uplifted by the possibility, and the nation's economy is the more solvent for the effort which he is able to make given understanding and the opportunity.

\title{
THE USER'S VIEWPOINT
}

\author{
By O. A. Denly, M.B.E., F.H.A. \\ Chairman, Disabled Drivers' Association
}

Patience. One of the first things a disabled person has to learn when facing the use of a wheelchair for the rest of his life is patience.

Patience to cope with architectural barriers.

Patience in waiting for improvements in the design of wheelchairs.

Patience to learn how to do things indirectly which can no longer be done directly.

Patience in waiting for others to learn that because something has been done a certain way for years it is not necessarily the best way.

Patience to learn how to surmount or ignore psychological barriers.

Patience in waiting to be taught how to make the best use of a wheelchair.

Patience in waiting for the powers that be at the Ministry of Health to learn that the active disabled wheelchair users cannot be brought down to the lowest common denominator of mass production in the issue of wheelchairs.

I am afraid that after nearly twenty years of living in a wheelchair my patience is fast running out, and I have many harsh things to say this morning. I am not unaware of the improvements that have been made-for example immediately after the last war there was not a single suitable folding transit wheelchair available 
in this country, and I had to import one from the United States. Only a few years back practically every wheelchair had the large propelling wheels at the front. Today we have progressed to the stage of approximately 95 per cent. of wheelchairs having the large wheels at the back. The reason is obvious-the ease of going up and down steps, and no campaign against architectural barriers is going to eliminate steps-but this transformation in the design of wheelchairs has not come about without a battle. Several years ago a senior Ministry official, when proudly showing off the first A.C. folding wheelchair with large wheels at the front, was challenged to get me down a flight of steps. Even with four men helping they made such a hash of it that I fell out. This same senior official offered to fit straps to the chair to prevent my falling out! Such was the progress in design. This fortunately occurred many years ago, but as I propose to demonstrate shortly we are not yet completely free from such prejudicial thinking.

As one who goes about his daily life in a wheelchair I expect my chair to be strictly functional, and I am not so concerned with the appearance of the chair or the effect it has on others. After reading Mrs. Raynar's article in Design in August last year, I am delighted that this morning's panel of speakers does not include a psychologist to enlarge upon wheelchairs that scream 'disablement', and the effect they have on wheelchair users, who either regress to dependent childhood patterns and demand help on all occasions, or become irascible and aggressive, refusing to accept any sort of help. Perhaps I fall into the latter category, hence my impatience, for which I make no excuses.

First. I should not be here at all. In the new manual Designing for the Disabled, just published, the provision of level approaches to public areas and access for wheelchair visitors is suggested under 'Exhibition Buildings'. The Polio Research Fund and the Building Exhibition should be the first to recognise this problem. Yet when organising this Symposium on the Wheelchair, they inform the wheelchair user of an L.C.C. regulation that people in wheelchairs attending must be accompanied by an able-bodied person. I came unaccompanied. The Polio Research Fund attempt to foster independence for the wheelchair user, and yet they fall into this trap. No wonder the wheelchair user has to battle with psychological barriers. Incidentally, there are level approaches for wheelchair visitors to Olympia, but it never occurred to the organisers to pass on this information to those attending in wheelchairs.

Second. A symposium is an Ancient Greek drinking-party, linked with a philosophical or other friendly discussion. In the modern idiom a set of papers on one subject from various points of view. This has happened, and I have the last word before lunch. But eight points of view is too much to stomach in one morning, and I am the first and only speaker who has to live with the wheelchair, and I find twenty minutes grossly inadequate to cover my subject. But I will be as quick as I can.

Third. The young-or better still the non-geriatric-active disabled wheelchair user, who has a lengthy period of living ahead of him both at work and pleasure, is getting a raw deal from the Ministry of Health. The whole question of design, issue and use of wheelchairs has got out of perspective. This I now propose to demonstrate. 
Perspective. We are told that the Ministry are issuing wheelchairs at the rate of approximately 23,000 a year, and they are nearly all the Model $8 \mathrm{~F}$, which the Ministry describe as the self-propelled folding chair for easy transportation. In Designing for the Disabled we read that approximately 15 per cent. of wheelchair users are independent or potentially independent, i.e. are able to transfer without assistance on and off a w.c. seat, into and out of a bath, on and off a bed, and into and out of a motor car or invalid tricycle. If 85 per cent of wheelchair users are that helpless, it is high time that something was done about it. Or is it that the bulk of the Ministry wheelchairs are going to old people, the rheumatoid and osteoarthritics, and the hemiplegics? I believe this is so, and their problems are quite different from the young active wheelchair user. But the cost-conscious standard specification officials at the Ministry do not take this into account, and so the young active wheelchair user suffers. It is for this group I speak this morning, and I make no pretence to cater for the other. When discussing the relative merits of pneumatic tyres and solid tyres on wheelchairs with a recently retired Ministry doctor, he told me that the Ministry were not in favour of pneumatic tyres because of the difficulty elderly people often had in pumping up the tyres. Need I say more.

Shortcoming of Model 8F. The width folded is given as io inches in the Ministry handbook. Try it for yourself. I suggest the natural folded width is II inches, due to the folding mechanism used. True the chair can be forced to a width of only Io inches, but often folding needs to be done quickly and with one hand by the occupant from the tricycle or car seat. The Everest and Jennings chair I am in is a recent private purchase. It can be folded easily to only Io inches. The single X-brace cannot be copied because of world patents. Alas this chair is not available under the National Health Service. Width of wheelchair is important when getting it between the front and back seats of a car.

Weight. The weight of the Model $8 \mathrm{~F}$ is listed at $54 \mathrm{lb}$. The last time I weighed one it was $56 \mathrm{lb}$. The standard E. and J. chair I use for work is only $42 \mathrm{lb}$. The weight of the chair I am in-it has certain refinements and solid tyres on the large wheels-is about $46 \mathrm{lb}$. Weight is an important factor. The extra Io lb. or so on the Ministry Model is too much. Pavements are seldom level at right angles to the direction of travel, and the weight factor comes in when trying to travel in a straight line. Able-bodied helpers suffer when having to lift heavy wheelchairs into boots or on to roofs of cars to make room inside the vehicle for the rest of the family. Extra weight also makes a difference when going up and down steps.

Many complaints have been received in the Disabled Drivers' Association about the increased weight of the Ministry chairs now issued. This applies particularly to getting a wheelchair into and out of a car or tricycle. A recent survey in the Association showed that 25 per cent. of the membership always used a wheelchair, and a further 30 per cent sometimes. Of those using tricycles, just over half could load their wheelchairs into the tricycle unaided, and of those using cars just under half could load their wheelchairs into the car unaided. Very different figures to those given in Designing for the Disabled. Of those carrying wheelchairs in cars 52 per cent carried them primarily in the boot, 35 per cent behind the front seats, 8 per cent on the back seat and 5 per cent. on the roof. A survey on the ease 
of getting into and out of cars with wheelchairs was clearly needed. A practical survey on these lines of 28 different makes and models of cars at the 1963 motor show will be appearing in the winter issue of The Magic Carpet, the quarterly magazine of the Disabled Drivers' Association. The three basic tests covered

(a) the ease of getting in and out,

(b) the ease of getting the wheelchair in and out,

(c) would the wheelchair fit in the boot (or the back of an estate car/shooting brake).

Incidentally the Model $8 \mathrm{~F}$ will not go in the boot of my Ministry issued car. The chair I am in will.

Why is the standard Ministry Model $8 \mathrm{~F}$ so much heavier than the E. and J. chair? The following are factors:

Detachable Armrests. Fitting detachable armrests adds $5 \mathrm{lb}$. to the weight of a chair. Yet all Ministry Model $8 \mathrm{~F}$ chairs are fitted with detachable armrests. These are necessary for some but not all users. The detachable armrests cannot be used for pulling the wheelchair into a tricycle or car. There is the danger when going down flights of steps of able-bodied helpers being left holding the armrests only! Look closely at some of the Model $8 \mathrm{~F}$ chairs in use. You will find little straps to keep the armrests in place! Perhaps we have not moved all that far from my earlier story.

Seriously disabled people have been taught to get in and out of wheelchairs without detachable armrests, because properly trained it is easier, and the simplicity in the design of the chair is not lost.

Incidentally, detachable armrests add to the overall width of the chair-25 inches on Model 8F; only 24 inches on the chair I am in, without detachable arms.

Pneumatic v. Solid Tyres. It is generally realised that solid tyres add $4 \mathrm{lb}$. to the weight of a chair. Pneumatic tyres act as shock absorbers on kerbs and steps, and the life of the chair is much longer. Modern pneumatic tyres are not difficult to keep pumped up. The disadvantages of pneumatic tyres are that they squeak on polished surfaces and require a slightly greater force to move from stationary. The ride over rough ground is much easier.

Front Castors. The 7 inch castor specified by the Ministry of Health for all their transit models weighs more than the 8 inch castor on the E. and J. chair. The rubber tyred front castors on the chair I am in are slightly lighter still.

Frame. The frame of the Model $8 \mathrm{~F}$ chair is heavier than the E. and J. chair. The folding mechanism is a significant factor.

How Compact is the Chair? The standard model $8 \mathrm{~F}$ will not go in the boot of most cars. Even with swinging detachable footrests, which are available on the Model $8 \mathrm{~F}$, the situation is little better. The survey at the motor show confirmed this. The overall height of 38 inches from the ground to the handles is the trouble. Folding back reduces overall height to only 30 inches. Swinging detachable footrests reduce overall length to $3 \mathrm{I}$ inches. 
Diameter of Propelling Wheels. On the standard Model $8 \mathrm{~F}$ they are 22 inches. Overall length 4I inches. This chair, 24 inches. Overall length 42 inches. I prefer the larger diameter wheels, in spite of the increased overall length, due to the increased ease of going up and down steps and kerbs.

Overall Length. Following remarks just made, there is a case for a second wheelchair in the home. For example, a Dingwall chair is available with only $20 \mathrm{inch}$ wheels and an overall length of only 36 inches. This makes life within the narrower confines of a home easier. It need not even be a folding chair, with the many advantages of design. The chair can be left in the garage when away at work, and is there all ready when returning tired at the end of the day. The transit chair can remain in the car, with further saving of effort.

Footrests. These are the most unsatisfactory feature of the design of both the Model 8F and the E. and J. chair. Heel straps are necessary to prevent paralysed legs and feet from sliding off the footrests. For some strange anthropometric reasons the footrests are sloped upwards towards the front at an angle of I 5 degrees from the horizontal. Able-bodied people sitting on chairs have their feet flat on the floor. Why is it different for a disabled wheelchair user? Heel straps dig into the back of paralysed calf muscles. When swinging detachable footrests are fitted, heel straps are out. When the chair is tipped backwards, either by the occupant or the attendant, for going up and down steps, slippery soles slide backwards off the metal footrests. Result-legs dangling.

This chair has just been fitted with rubber insert footrests, which is a partial answer. But a completely new design of footrest is required. I have had a mock-up made recently, and it is currently under examination at the E. and J. Bridgend factory. But it is a sad indictment that a wheelchair user has to initiate such research. No actual research is being carried out by the Ministry, and it should.

Wheelchair Narrower. Often the wheelchair user is faced in an emergency with a narrow doorway, such as a lift door or bathroom doorway in a hotel. There are two ways of overcoming this:

(a) Means of narrowing wheelchair while still in the wheelchair, without use of any mechanical aid.

(b) Wheelchair narrower. The first public demonstration of wheelchair narrower was developed by Zimmer Orthopaedic from American design. Wheelchair can be narrowed 3 inches while remaining on slung seat. Overall width reduced from 24 inches to $2 \mathrm{I}$ inches.

Having dealt rapidly with the design of the wheelchair, I turn to two other important features: first, the issue of a wheelchair; second, instruction in the use of a wheelchair.

The Issue of a Wheelchair. The present method of prescribing a wheelchair under the National Health Service is far from satisfactory. I quote from an American hospital:

'The Physical Therapy Department has I08 wheelchairs of various designs and combinations available for patient use during the trial period when 
a wheelchair evaluation is ordered by the physiatrist. The actual "use itlive with it" method cuts down greatly on errors in the final specification thereby saving a considerable amount of expense and needless anxiety to the patient.'

I now quote a recent British example. A retired civil servant, aged 65, was admitted to hospital as an emergency with an embolism of the femoral artery. He was discharged three months later with a mid-thigh amputation left leg and aboveknee amputation right leg. Surgeon prescribes a wheelchair. Almoner fills in A.O.F.5, which is sent to Appliance Centre on same day as patient is discharged home. One month later patient changes his mind and asks hospital for propelling wheels at the rear instead of front of wheelchair (he has been doing a bit of research at home) and also asks for pneumatic tyres. Two months later wheelchair is delivered to patient at his home. He rings Appliance Centre stating that wheelchair is too small. He requires a wider seat. Appliance Centre write to hospital stating no particular size of seat was recommended on the form A.O.F.5 and the standard size seat I 7 inches by 17 inches was therefore supplied. The Almoner's observations would be appreciated. And so on. And so on. I can vouch for the truth of this story. It happened in my own hospital. Unfortunately I only heard about it towards the end of the tale, or should I say the middle, as it may be another three months before the right chair can be supplied. The surgeon did not even know of the existence of the Ministry Handbook of invalid chairs. The Almoner, who worked from the handbook, thought that every patient prescribed a wheelchair was seen and tried out by a Technical Officer at the Appliance Centre. The Technical Officer said he was far too busy to see every patient prescribed a wheelchair. True there is a Ministry Handbook. True there are different types of wheelchairs on view at Appliance Centres, and surgeons, physicians, almoners, physiotherapists and occupational therapists are welcome to visit these centres. But do they? King's College Hospital are an exception. They run their own wheelchair clinic once a month. But probably up and down the country there are variations of my story going on all the time. Time does not permit my enlarging on this subject, but take a close look when you can at page 5 of the Ministry Handbook describing the Model 8F. I find it hard enough to visualise different patients in the different wheelchairs even though I live in one. How much more difficult it must be for the doctor prescribing. Just one example. The standard seat width is given as 17 inches. Is this between the frames, which is the critical width for getting in and out, or the total width of the seat? This chair is 16 inches between the frames but has a seat width of $\mathrm{I} 8$ inches. There is only one way to prescribe a wheelchair for a patient: the actual 'use it-live with it' method.

Using a Wheelchair. It has puzzled me for a long time that so little thought has been given to teaching people to use wheelchairs. There is at present no practical training given, except perhaps for a little basic training in getting into and out of bed or the bath, at a few centres. At Stoke Mandeville Hospital there is probably the greatest number of young active wheelchair users together at any one time. I hope that Dr. Guttmann or Dr. Walsh can prove me wrong, but I am left with the impression that even there, little specific research or training in this aspect is carried out.

Patients are not taught how to tip their wheelchair on the back wheels. How 
to negotiate loose rugs. How to go up and down kerbs, first attended and then unattended. How to go up and down steps and stairs in a wheelchair with an attendant. How to cross a main road unattended. How to go down a steep slope unattended. How the male can urinate without the use of a bottle and without leaving the wheelchair. How to get in and out of a tricycle or car from a wheelchair. How to get a wheelchair in and out of tricycle or car unaided. How to narrow a wheelchair to go through a narrow doorway, either unaided or with an attendant. How to change a car wheel from a wheelchair. How to get from a wheelchair to the floor and back. How to go down a flight of steps unaided. Too much of this has been learned by word of mouth from one disabled person to another. There are still cases of wheelchair users buying a car and having hand controls fitted and then finding they cannot get the wheelchair in unaided.

Reports, to be published by the Disabled Drivers' Association, will help. But there is also need for an illustrated handbook for wheelchair users covering all the techniques just mentioned, and all the variations in design mentioned earlier. There is also need for an instructional film as so many of these techniques are a matter of correct positioning and movement. There is also need to teach ablebodied people how to handle a wheelchair occupant, particularly when taking them up and down flights of steps.

The nearest approach to such a booklet is the Owner's Manual issued to those who purchase privately an Everest and Jennings wheelchair. This is excellent so far as it goes, but this is a need which should be tackled by someone other than a manufacturer of wheelchairs. It is pertinent to ask what the Ministry of Health are doing about it?

The handbook and film when completed could be circulated to rehabilitation departments, physiotherapists, occupational therapists and recipients of wheelchairs, and to any voluntary organisations concerned with mobility for the disabled. The recipient of an artificial limb is trained in its use. Why not also the recipient of a wheelchair?

\section{SUMMARY}

I. All is not well with the design of wheelchairs issued by the Ministry of Health to young active disabled people who will need to use a wheelchair for many years to come both at work and for pleasure.

A distinction should be made between the young active disabled and the elderly disabled, and cost consideration should not prevent the right chair, and the right number of chairs, being issued to the young active disabled group. At the present time the E. and J. compact transit chair in which I am sitting is nearest to the ideal for use outside the home. It is not available under the National Health Service. It should be made available forthwith.

2. All is not well with the method of prescribing wheelchairs under the National Health Service. The Ministry Handbook should be revised and enlarged, and the 'use it-live with it' method introduced.

3. A detailed illustrated handbook and film on how to get the best use out of a wheelchair should be prepared and issued to all concerned. 